\title{
Peningkatan Pengetahuan Masyarakat Mengenai Pencegahan Penyakit Tuberculosis Pada Masa Pandemi Covid-19
}

\author{
Novendy ${ }^{1 *}$, Alvin Rinaldo ${ }^{2}$, Sanity Savant Suhendar ${ }^{3}$, \\ Fransisca Novianti ${ }^{4}$, William Tanaka ${ }^{5}$ \\ ${ }^{1}$ Bagian Ilmu Kesehatan Masyarakat, Fakultas Kedokteran Universitas Tarumanagara, Jakarta, Indonesia \\ ${ }^{2345}$ Mahasiswa Program Studi Profesi Dokter, Fakultas Kedokteran Universitas Tarumanagara, \\ Jakarta, Indonesia \\ Author E-mail: novendy@fk.untar.ac.id
}

\begin{abstract}
A B S T R A K
Angka kejadian penyakit tuberkulosis di wilayah kerja Puskesmas Kronjo masih tinggi. Salah satu faktor yang dapat menyebabkan tingginya angka kejadian penyakit tuberkulosis adalah rendahnya pengetahuan. Maka perlu dilakukan kegiatan bakti kesehatan dalam rangka meningkatkan pengetahuan masyarakat mengenai penyakit tuberkulosis. Metode yang digunakan dalam kegiatan bakti kesehatan ini adalah memberikan edukasi kepada masyarakat. Peningkatan pengetahuan dinilai dengan hasil pretes dan postes. Nilai batas pengetahuan baik yang diambil untuk pretes dan postes adalah di atas atau sama dengan 70 . Kegiatan bakti kesehatan dilakukan pada tanggal 13 September 2021 di aula Puskesmas Kronjo. Sebanyak 32 orang peserta yang sedang menunggu ikut dalam kegiatan ini. Hasil prestes didapatkan sebanyak $37.5 \%$ peserta dengan nilai pretes diatas atau sama dengan 70 . Hasil postes didapatkan sebanyak $87.5 \%$ peserta dengan nilai postes diatas atau sama dengan 70 . Hal ini menunjukkan adanya peningkatan sebanyak $50 \%$ peserta yang nilai postesnya diatas atau sama dengan 70. Maka dapat disimpulkan bahwa kegiatan bakti kesehatan yang telah dilakukan dapat meningkatkan jumlah peserta yang bertambah pengetahuannya. Peningkatan ini diharapkan dapat meningkatkan kewaspadaan masyarakat terhadap penyakit tuberculosis. Masyarakat yang ikut dalam kegiatan ini dapat menyebarkan informasi mengenai penyakit ini kepada masyarakat lain yang belum sempat hadir, sehingga diharapkan dapat terjadi eradikasi kasus penyakit tuberkulosis di Indonesia.
\end{abstract}

Kata Kunci: Tuberkulosis, Edukasi, Bakti Kesehatan.

\section{A B S T R A C T}

The Puskesmas Kronjo still has a high tuberculosis rate. One of the factors that contribute to the high incidence of tuberculosis is a lack of knowledge. As a result, health service activities are required to increase public awareness of tuberculosis. The method used in this health-care activity is to educate the community. The pretest and posttest results were used to assess the increase in knowledge. The limit 
value of good knowledge for the pretest and posttest is greater than 70 . The health service activity took place on September 13, 2021, in the Puskesmas Kronjo's hall. There was a total of 32 people who took part in this activity. Pretest results were obtained by $37.5 \%$ of participants with a pretest score greater than 70 . The posttest result was obtained by $87.5 \%$ of the participants with a posttest score greater than 70 . This represents a $50 \%$ increase in the number of participants with posttest scores greater than 70. As a result, it is possible to conclude that the health-care activities that have been carried out had increased the number of participants who had increased their knowledge. This increase is expected to raise public awareness of tuberculosis, and those who participated in this activity will be able to disseminate information about the disease to others who were unable to attend, allowing for the eradication of tuberculosis cases in Indonesia.

Keywords: Tuberculosis, Education, Health Service.

Copyright (c) 2021 Authors. This is an open access article distributed under the Creative Commons Attribution License, which permits unrestricted use, distribution, and reproduction in any medium, provided the original work is properly cited.

\section{PENDAHULUAN}

Sebelum pandemi Covid-19, upaya penanggulangan penyakit tuberkulosis (TBC) oleh sejumlah negara sudah menunjukkan hasil yang cukup baik dan cenderung stabil. Hal ini terlihat dari adanya penurunan angka kasus insiden sebesar 9\% dan penurunan angka kematian sebesar $14 \%$ antara tahun 2015 sampai 2019. Indonesia sendiri juga berkomitmen untuk mewujudkan penurunan kasus TBC dengan penyelenggaraan acara Gerakan Maju Bersama Menuju Eliminasi Tuberkulosis (TBC) 2030 pada bulan Januari 2020 di Cimahi yang turut dihadiri oleh Presiden RI Joko Widodo serta sejumlah pemerintah daerah dari seluruh Indonesia. Acara ini dilakukan dengan mengingat bahwa Indonesia merupakan salah satu negara dengan peringkat 5 besar dunia untuk kasus kejadian penyakit tuberkulosis. (Kementerian Kesehatan RI, 2018; Meyla \& Afredo, 2020).

Upaya penanggulangan pandemi Covid-19 masih belum berakhir. Bahkan setiap hari masih terus terdapat penambahan jumlah kasus baru. Kondisi ini pasti akan berdampak pada mundurnya layanan untuk penanggulangan penyakit TBC. Hal ini dikarenakan bahwa sumber daya manusia, keuangan, dan sumber daya lainnya telah dialokasikan untuk penanganan Covid-19. Bahkan sistem pengumpulan dan pelaporan data juga terkena dampak negatif dan terfokus pada penyakit Covid-19 (Meyla \& Afredo, 2020).

Berdasarkan hasil laporan Badan Kesehatan Dunia dalam Global TB Report 2020, disebutkan bahwa sekitar 1,4 juta orang meninggal karena penyakit terkait TBC pada 2019 (WHO, 2020). Diperkirakan sebanyak 10 juta orang terkena TBC, dan terdapat sekitar 3 juta orang yang lain yang tidak terdiagnosis, atau tidak dilaporkan secara resmi ke dalam sistem pelaporan nasional (WHO, 2020). Kondisi ini makin dipersulit dengan pasien TBC yang resistan terhadap obat, dimana diperkirakan sekitar 465.000 orang baru didiagnosis dengan TBC dan resistan terhadap obat TBC pada tahun 2019 dan kurang dari 40\% yang dapat mengakses pengobatan tersebut (WHO, 2020). Dari hasil laporan Global TB Report 2020 yang telah dikumpulkan dari lebih 200 negara, juga telah menunjukkan adanya penurunan yang signifikan dalam angka notifikasi kasus TBC (WHO, 2020). Penurunan tersebut mencapai sebesar $25-30 \%$ antara bulan Januari hingga Juni 2020 bila dibandingkan dengan periode yang sama pada tahun 2019 dari 3 negara dengan beban tinggi, termasuk Indonesia (WHO, 2019). Penurunan angka notifikasi kasus ini dapat menyebabkan peningkatan yang drastis dalam angka kematian akibat TBC (WHO, 2020).

Penyakit tuberkulosis merupakan salah satu 
penyakit menular yang cukup mematikan di dunia. Namun penyakit ini dapat dicegah dan disembuhkan asal mendapatkan penanganan yang benar. Berdasarkan data yang ada, sebanyak $85 \%$ kasus dapat disembuhkan dengan pengobatan yang tepat selama 6 bulan. Salah satu faktor yang sering menyebabkan gagalnya pengobatan TBC dapat disebabkan oleh tingkat pengetahuan masyarakat akan penyakit ini masih rendah. Menurut Arikunto yang dikutip oleh Wawan dan Dewi dalam bukunya yang berjudul "Teori dan Pengukuran Pengetahuan, Sikap, dan Perilaku Manusia tahun 2016, menyatakan bahwa pengetahuan seseorang dapat diketahui dan diinterpretasikan dengan skala kualitatif (Wawan \& Dewi, 2016). Intepretasi tersebut dapat dinyatakan sebagai: baik, bila hasil persentase 76\%-100\%; cukup, bila persentase 56\%-75\%; dan kurang, bila hasil persentase $<56 \%$ (Wawan \& Dewi, 2016).

Pengetahuan yang baik, mengenai penyakit TBC ini sebagai contoh adalah mengetahui bagaimana cara pencegahan hingga bagaimana cara menuntaskan pengobatan yang akan membawa hasil yang baik dalam penyembuhan penyakit ini. Seperti yang tertuang dalam Peraturan Presiden Republik Indonesia Nomor 67 tahun 2021 bahwa intensifikasi upaya kesehatan dalam rangka penanggulangan penyakit TBC dapat dilakukan melalui 5 cara, yaitu: promosi kesehatan; pengendalian faktor risiko; penemuan dan pengobatan; pemberian kekebalan dan pemberian obat pencegahan (JDIH BPK RI, 2021).

Hal pertama yang dilakukan dalam upaya tersebut adalah melakukan promosi kesehatan. Promosi kesehatan sebagaimana yang dimaksud dalam keputusan ini adalah meningkatkan pengetahuan, kesadaran dan perubahan perilaku masyarakat mengenai penyakit TB (JDIH BPK RI, 2021). Sebuah penelitian yang dilakukan oleh Luba et al tahun 2014 di Lesotho mendapatkan bahwa, secara keseluruhan pengetahuan umum mengenai penyakit TBC pada masyarakat Lesotho termasuk cukup (59.9\%) (Luba et al, 2019). Namun terdapat perbedaan signifikan antara responden perempuan dengan responden laki-laki (masing - masing 67.0\% vs $41.8 \%$ ) (Luba et al, 2019). Mengingat pada masa pandemi Covid-19, semua mata tertuju pada penyakit tersebut, maka banyak penyakit yang cukup mematikan sempat diabaikan. Maka dengan ini, tim merasa perlu kembali mengedukasi masyarakat bahwa masih banyak penyakit infeksi yang mematikan selain penyakit Covid-19. Dengan kegiatan ini diharapkan masyarakat dapat lebih waspada akan penyakit infeksi lain selain penyakit Covid-19, yaitu dalam hal ini penyakit TBC.

\section{METODE PELAKSANAAN}

Pelaksanaan PKM adalah memberikan edukasi kesehatan berupa penyuluhan dan pemutaran video terkait informasi dalam upaya meningkatkan pengetahuan akan penyakit tuberkulosis. Materi penyuluhan yang dipaparkan terkait penyakit TBC berupa informasi definisi, tanda dan gejala penyakit, pemeriksaan, bentuk pengobatan, cara pencegahan, hingga komplikasi yang mungkin terjadi. Penyuluhan disampaikan dengan menggunakan poster. Sementara pemutaran video yang dilakukan terkait informasi mengenai cara beretika batuk dengan baik dan benar. Sasaran dari kegiatan ini adalah warga di Kecamatan Kronjo, Kabupaten Tangerang yang dilakukan secara luring di Puskesmas Kecamatan Kronjo. Kegiatan ini dilakukan dengan memperhatikan protokol kesehatan. Pengukuran dampak penyuluhan dilakukan secara kuantitatif melalui penilaian peningkatan pengetahuan dari hasil pretest dan posttest dengan 15 pertanyaan terkait dengan materi penyuluhan yang disampaikan sebesar $50 \%$.

\section{HASIL DAN PEMBAHASAN}

Kegiatan PKM dilakukan pada tanggal 13 September 2021, mulai pukul 09.00 - 10.30 WIB. Para pengunjung Puskesmas yang sedang menunggu diminta waktunya untuk dapat mengikuti kegiatan bakti kesehatan di Aula Puskesmas. Sebelum memulai kegiatan, peserta terlebih dahulu diminta untuk mengisi pretes. 


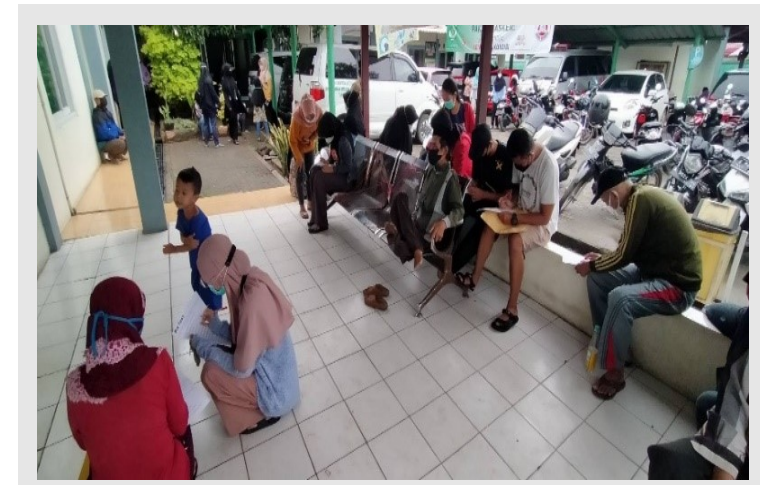

Gambar 1. Peserta sedang mengerjakan soal pre tes

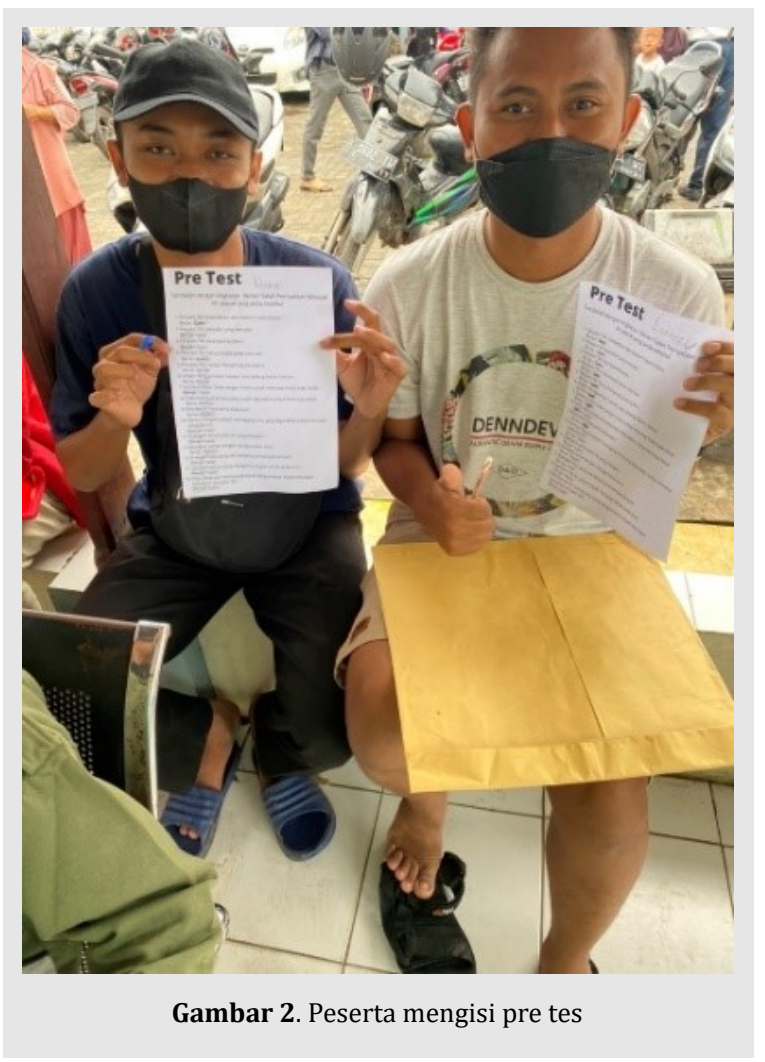

Kegiatan yang dilakukan telah sesuai dengan salah satu upaya penanggulangan penyakit TBC yang telah dicanangkan oleh Pemerintah yaitu dengan melakukan promosi kesehatan. Total sebanyak 32 orang peserta yang ikut dalam kegiatan bakti kesehatan ini. Dari 32 peserta tersebut terdapat sebanyak 11 (34.6\%) peserta berjenis kelamin laki-laki dan sebanyak 21 (65.6\%) peserta berjenis kelamin perempuan. Rata-rata usia peserta adalah 38,2 tahun dengan rentang usia peserta antara 24-65 tahun. Hasil pretes didapatkan nilai rata-rata sebesar 61.25 poin dan postes nilai rata-rata sebesar 75 poin. Berdasarkan hasil dan kriteria dari Arikunto, maka tingkat pengetahuan peserta yang ikut dalam kegiatan bakti kesehatan ini dikatakan cukup. Perhitungan tingkat pengetahuan peserta ditentukan dengan nilai cut off sebesar 70, yang diambil dari hasil pembagian rata-rata nilai pretes dan postes. Maka dari hasil prestes didapatkan sebanyak 12 (37.5\%) peserta yang nilai pretesnya diatas sama dengan 70 , dan hasil postes didapatkan sebanyak $28(87.5 \%)$ peserta yang nilai postesnya diatas sama dengan 70 . Sehingga terdapat sebanyak $50 \%$ peserta yang meningkat pengetahuannya setelah mengikuti kegiatan bakti kesehatan ini. Hasil ini cukup sejalan dengan penelitian yang dilakukan oleh Luba et al (2019) yang mendapatkan secara umum pengetahuan responden mengenai penyakit TBC adalah cukup baik yaitu sebesar 59.9\% (Luba et al, 2019). Data selengkapnya dapat dilihat pada tabel 1 yang diikuti dengan gambar poster serta pemberian hadiah pada acara penyuluhan TBC.

Table 1. Hasil Kegiatan Bakti Kesehatan

\begin{tabular}{lllc}
\hline Variabel & Proporsi N = 32 (\%) & Mean:SD & Median (min - maks) \\
\hline Jenis Kelamin & & \\
\hline Laki-laki & $11(34.6)$ & & \\
\hline Perempuan & $21(65.6)$ & & \\
\hline Usia (tahun) & & $36.2 ; 11.59$ & \\
\hline Hasil pretes & & & $60(40-70)$ \\
\hline$<70$ & $20(62.5 \%)$ & $61.25: 8.33$ & \\
\hline$\geq 70$ & $12(37.5 \%)$ & & $75(60-100)$ \\
\hline Hasil pretes & & $75.00 ; 9.16$ & \\
\hline$<70$ & $4(12.5 \%)$ & & \\
\hline$\geq 70$ & $28(87.5 \%)$ & & \\
\hline
\end{tabular}



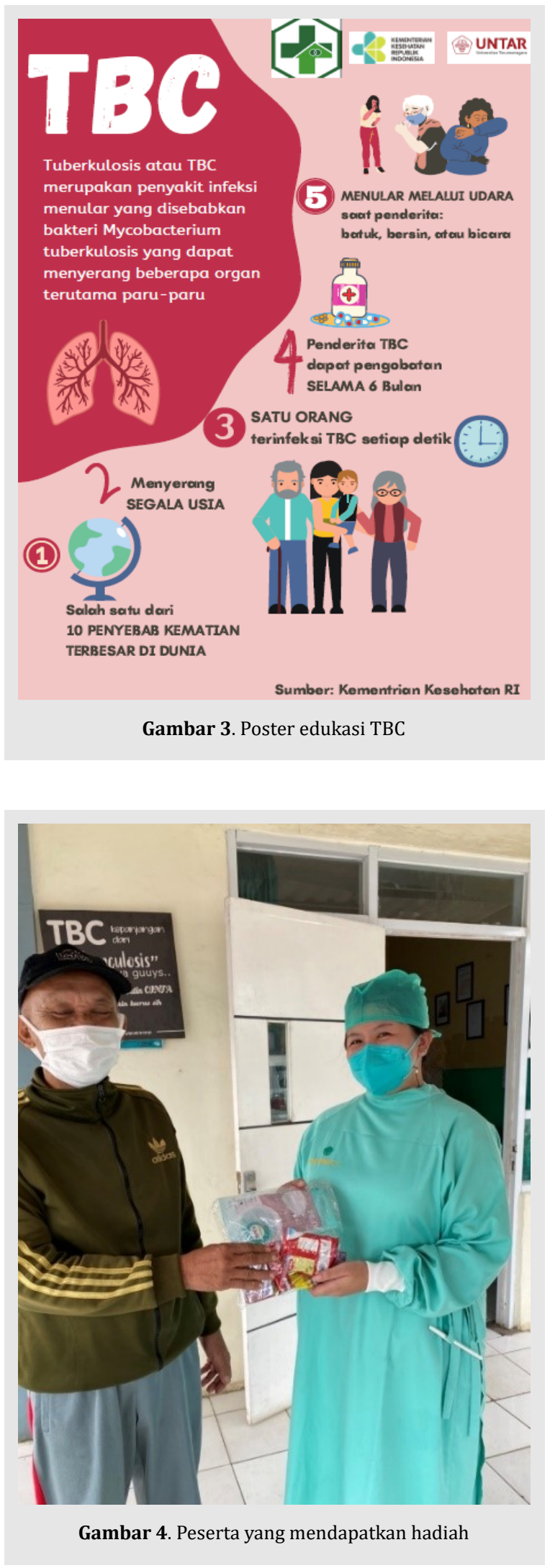

\section{KESIMPULAN DAN SARAN}

Kegiatan bakti kesehatan untuk meningkatkan pengetahuan kepada masyarakat mengenai penyakit tuberculosis telah berjalan dengan baik dan lancar. Seluruh peserta dapat mengikuti kegiatan ini dengan baik. Hasil pretest dan posttest menunjukkan bahwa sebanyak 50\% peserta meningkat pengetahuannya dalam hal pemahaman terhadap tuberkulosis. Hasil ini sesuai dengan target yang ditetapkan, dan menunjukkan bahwa kegiatan edukasi yang telah diberikan kepada masyarakat dapat meningkatkan pengetahuan masyarakat mengenai penyakit tuberkulosis. Maka diharapkan peningkatan pengetahuan ini membuat masyarakat dapat lebih waspada terhadap penyakit tuberkulosis, dan dapat menyebarkan informasi mengenai penyakit ini kepada masyarakat lain yang belum sempat mengikuti kegiatan bakti kesehatan ini. Sehingga kegiatan yang telah dilakukan ini dapat diteruskan ke tempat-tempat yang berada di wilayah kerja Puskesmas Kronjo. Diharapkan agar acara ini dapat berlanjut secara berkesinambungan dengan demikian eradikasi penyakit tuberkulosis di Indonesia dapat terjadi pada tahun 2030.

\section{Ucapan Terima Kasih}

Ucapan terima kasih kami sampaikan kepada Lembaga Penelitian dan Pengabdian kepada Masyarakat Universitas Tarumanagara atas pendanaan kegiatan ini, sehingga kegiatan bakti kesehatan dapat terlaksana dengan baik. Terima kasih juga disampaikan kepada Kepala Puskesmas Kecamatan Kronjo dan staf, serta seluruh peserta yang telah mengikuti kegiatan bakti kesehatan ini.. Terima kasih juga disampaikan kepada Pimpinan Universitas Tarumanagara dan Pimpinan Fakultas Kedokteran Universitas Tarumanagara atas dukungannya dalam pelaksanaan kegiatan ini. 


\section{R E F E R E N C E}

JDIH BPK RI. (2021). Peraturan Presiden Republik Indonesia No.67 Tahun 2021 tentang Penanggulangan Tuberkulosis. Retrieved from: https://peraturan.bpk.go.id/Home/Details/174557/perpresno-67-tahun-2021 [08 September 2021]

Kementerian Kesehatan Republik Indonesia. (2018). Tuberkulosis: Dicari para pemimpin untuk dunia bebas TBC. Retrieved from: https://pusdatin.kemkes.go.id/resources/download/pusdatin/ infodatin/infodatin-tuberkulosis-2018.pdf. [08 September 2021]

Luba, T.R., Tang, S.F., Liu, Q.Y., Gebremedhin, S.A., Kisasi, M,D, \& Feng, Z.C. (2019). Knowledge, attitude ann associated factors towards tuverculosis in Lesotho: a population based study. BMC Infekcious Disease. 19:96. doi: https://doi.org/10.1186/s12879-019-3688-x [16 September 2021]

Meyla \& Alfredo, R. (2020). Global TB Report 2020: Bagaimana Capaian Penanganan Tuberkulosis Di Tengah Pandemi Covid-19?. Yayasan KNCV Indonesia Eliminasi Tuberkulosis. Retrieved from: https://yki4tbc.org/news-default/411-global-tb-report-2020-bagaimana-capaian-penanganantuberkulosis-di-tengah-pandemi-covid-19.html [30 Agustus 2021]

Wawan, A \& Dewi, M. (2016). Teori \& pengukuran pengetahuan sikap dan perilaku manusia. Yogyakarta: Nuha Medika.

World Health Organization. (2020). Global tuberculosis report 2020. Retrieved from: https://www.who.int/publications/i/item/9789240013131 [09 September 2021] 